\title{
Current Harmonics Cancellation in Three-Phase Four-Wire Systems by Using a Four-Branch Star Filtering Topology
}

\author{
Pedro Rodríguez, Member, IEEE, J. Ignacio Candela, Member, IEEE, Alvaro Luna, Student Member, IEEE, \\ Lucian Asiminoaei, Member, IEEE, Remus Teodorescu, Senior Member, IEEE, and Frede Blaabjerg, Fellow, IEEE
}

\begin{abstract}
This paper presents a new solution for filtering current harmonics in three-phase four-wire networks. The original four-branch star (FBS) filter topology presented in this paper is characterized by a particular layout of single-phase inductances and capacitors, without using any transformer or special electromagnetic device. Via this layout, a power filter, with two different and simultaneous resonance frequencies and sequences, is achieved-one frequency for positive-/negative-sequence and another one for zero-sequence components. This filter topology can work either as a passive filter, when only passive components are employed, or as a hybrid filter, when its behavior is improved by integrating a power converter into the filter structure. The paper analyzes the proposed topology, and derives fundamental concepts about the control of the resulting hybrid power filter. From this analysis, a specific implementation of a three-phase four-wire hybrid power filter is presented as an illustrative application of the filtering topology. An extensive evaluation using simulation and experimental results from a DSP-based laboratory prototype is conducted in order to verify and validate the good performance achieved by the proposed FBS passive/hybrid power filter.
\end{abstract}

Index Terms-Active power filters, hybrid power filters, passive power filters, power line filters, power system harmonics, reactive power control.

\section{INTRODUCTION}

$\mathbf{I}$ NTERNATIONAL standard regulating current harmonics in distribution networks [1]-[3] reflects the importance of the problem originated by current harmonics in terms of power quality, reliability, and continuity of supply, mainly at low-voltage (LV) levels. Current harmonics in distribution grids mostly result from the widespread usage of nonlinear loads. Discharge lamps and power-electronics-based equipments are two frequent examples of nonlinear loads in residential, commercial, and industrial facilities. Currents harmonics also have a significant effect on medium-voltage (MV) and LV networks due to the

Manuscript received November 11, 2007; revised February 24, 2008. Current version published August 12, 2009. This work was supported by the Ministerio de Ciencia y Tecnologia of Spain under Grant PR2006-0411, and Project ENE2007-67878-C02-00/ALT and Project ENE2008-06841-C02-01/ALT. Recommended for publication by Associate Editor M. G. Simoes.

P. Rodriguez, J. I. Candela, and A. Luna are with the Department of Electrical Engineering, Technical University of Catalonia, Barcelona 08222, Spain (e-mail: prodriguez@ee.upc.edu; candela@ee.upc.edu; luna@ee.upc.edu).

L. Asiminoaei is with the Danfoss Drives A/S, Graasten DK-6300, Denmark (e-mail: 1as@danfoss.com).

R. Teodorescu and F. Blaabjerg are with the Institute of Energy Technology, Aalborg University, Aalborg DK-9220, Denmark (e-mail: ret@iet.aau.dk; fbl@iet.aau.dk).

Digital Object Identifier 10.1109/TPEL.2009.2017810 existence of singular loads such as furnace ovens and highpower line rectifiers.

Three-phase three-wire loads generate positive-/negativesequence (pn-seq) current harmonics. These harmonics give rise to resonances, voltage distortion, overheating, increase in losses, malfunction and premature ageing of electrical equipments, etc. Single-phase nonlinear loads are usually connected between the phase and neutral conductors, and, additionally, originate zerosequence (z-seq) current harmonics-typically with 3rd, 9th, and 15 th harmonic order. Harmonics with order of multiple of three resulting from several single-phase loads are summed up in the neutral conductor, which can result in a harmonic current in the neutral conductor up to three times higher than in the phase ones. Z-seq harmonic currents, also causing characteristic problems related to pn-seq harmonic currents, can give rise to neutral conductor overload, common mode neutral to earth voltages, increase of phase voltage distortion, and transformers overheating [4].

Shunt-connected current power filters can be classified as follows.

1) Shunt passive power filters (SPPFs) [5], [6]: Each one of these shunt filters is designed to offer a very low impedance path to current harmonics at the tuning frequency. Main advantages of the SPPFs are their simplicity and low cost. However, these advantages are, in fact, shadowed because of the dependence of the filtering characteristic on the grid impedance. Resonance frequency of the SPPF is also modified by parameters tolerance and filter ageing. Additionally, the usage of SPPF implies losses at the fundamental grid frequency, and can result in parallel/series resonances.

2) Shunt active power filters (SAPFs) [7]: These filters exploit a power-electronics-based power converter working in closed-loop mode as a current source. SAPFs are able to cancel out harmonics and unbalance from the load current, which results in sinusoidal balanced current at fundamental frequency flowing toward the source side. Even though SAPF can filter current harmonics in a very precise form, their cost is relatively high, which slows down their largescale application in distribution networks.

3) Shunt hybrid power filters (SHPFs) [8]-[10]: These filters result from the combination of passive and active power filters taking advantages from both of them. SHPF exhibits a fairly good filtering characteristic, which is almost independent of the grid impedance. Moreover, the cost of a 
SHPF is substantially lower than in the case of a SAPF. This cost reduction is mainly due to the low power rate of the power converter used in SHPF.

SPPF are conventionally based on simple resonant cells, and have only one resonance frequency, being designed to predominantly drain current away at such resonance frequency. Therefore, it is necessary to install as many individual $L C$ filters as characteristic current harmonics should to be canceled out. SPPF are not typically applied to cancel the third-order current harmonic, the highest among the z-seq current armonics. If an SPPF was tuned at the third harmonic, the resonance frequency of the $L C$ resonant cell would be very close to the fundamental frequency, typically $50 / 60 \mathrm{~Hz}$. As a consequence, the current absorbed by the filter at the fundamental frequency, for a reasonable quality factor, would be around the current drained at the third harmonic, which would make this filtering solution economically unviable.

Some of the techniques commonly applied to cancel z-seq current harmonics in electrical networks are as follows.

1) Shunt zig-zag reactors [11]: These kinds of reactors present very low impedance to the z-seq current components.

2) Passive LC power filters with a very high-quality factor [5]: The bandwidth of these passive filters is drastically reduced with the aim of reducing the maximum current absorbed at the fundamental frequency. However, they are easily detuned because of parameter tolerance, aging, and influence of the network.

3) Third-harmonic blocking power filters in series with the neutral conductor [12]: These filters act as highimpedance blocks to the third-harmonic current. This high impedance limits current flowing through the neutral conductor but deteriorates the phase to neutral voltage.

4) Active and hybrid filters [13]: These filters are based on power converters, sometimes using particular transformer configurations. Power converters allow controlling the filtering characteristic, making this kind of filter very suitable to efficiently cancel out z-seq current harmonics.

This paper presents an interesting solution for filtering current harmonics in three-phase four-wire networks. The proposed filter is based on a four-branch star (FBS) topology characterized by a particular layout of single-phase inductors and capacitors, without using any transformer or special electromagnetic device. Via this layout, a power filter, with two different and simultaneous resonance frequencies and sequences, is achieved, i.e., one frequency for pn-seq and another one for z-seq components. The resonant cells constituting the branches of the FBS filter are designed to drain away either one or several pn-seq components among the 5th-, 7th-, 11th-, and 13th-order harmonics plus either one or several z-seq components among the 3rd, 9th, and 15th current harmonics.

The FBS filter topology can work either in passive mode, when only passive components are employed, or in hybrid mode, when a power converter is integrated into the FBS structure to improve its filtering performance.

In the following, the FBS topology is introduced and some of its most interesting variants are highlighted. A three-phase four-

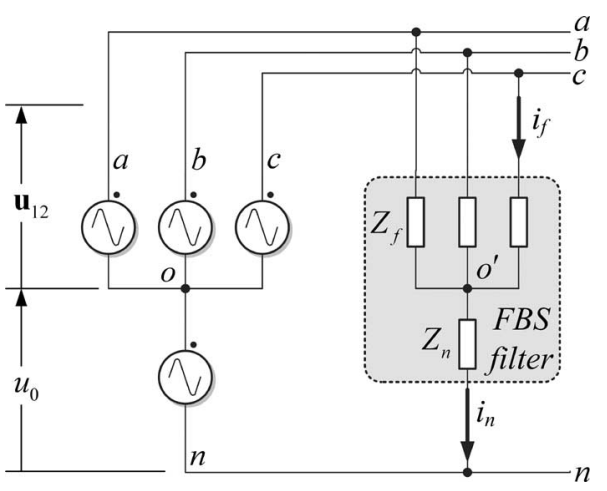

Fig. 1. FBS power filter with generic branch impedances.

wire hybrid power filter is chosen as a preferred implementation of the FBS topology, being analyzed and evaluated by both simulations and experiments.

\section{FBS POWER FILTER TOPOLOGY}

\section{A. General Structure of the FBS Power Filter}

The general structure of the shunt power filter topology proposed in this paper is shown in Fig. 1. The pn-seq and the z-seq voltage components of the three-phase network that the filter is connected to are also represented in Fig. 1. The FBS topology consists of three phase branches with three identical single-phase impedances $Z_{f}$ and one neutral branch with a fourth single-phase impedance $Z_{n}$.

In Fig. 1, the FBS power filter is connected to a generic three-phase network in which pn-seq voltage components $\mathbf{u}_{12}=$ $\left[u_{a o}, u_{b o}, u_{c o}\right]$ and z-seq voltage components $u_{0}$ have been represented separately for the sake of clarifying the superposition analysis presented in the following.

When only pn-seq components are considered in the circuit of Fig. 1, i.e., when it is assumed that $u_{0}=0$, the center nodes at the source and filter sides $\left(o-o^{\prime}\right)$ are virtually connected, and hence, $v_{o o^{\prime}}=0$. Therefore, the pn-seq impedance of the FBS power filter at a particular frequency $\vec{Z}_{12}$ is given by the following quotient of phasors:

$$
\vec{Z}_{12}=\frac{\vec{U}_{12}}{\vec{I}_{12}}=\frac{\vec{U}_{f o}}{\vec{I}_{f}}=\frac{\vec{U}_{f o^{\prime}}}{\vec{I}_{f}}=\vec{Z}_{f}, \quad \text { with } f=\{a, b, c\}
$$

where $\vec{U}_{12}$ and $\vec{I}_{12}$ are the pn-seq voltage and current phasors affecting the FBS filter, respectively.

Likewise, when only z-seq are considered in circuit of Fig. 1, i.e., when $\mathbf{u}_{12}=[0,0,0]$, the $\mathbf{z}$-seq impedance of the FBS power filter at a particular frequency $\vec{Z}_{0}$ is given by

$$
\vec{Z}_{0}=\frac{\vec{U}_{0}}{\vec{I}_{0}}=3 \frac{\vec{U}_{o n}}{\vec{I}_{n}}=\frac{\vec{U}_{o^{\prime} n}}{\vec{I}_{n}} \frac{\vec{Z}_{f}+3 \vec{Z}_{n}}{\vec{Z}_{n}}=\vec{Z}_{f}+3 \vec{Z}_{n}
$$

where $\vec{U}_{0}$ and $\vec{I}_{0}$ are the z-seq voltage and current phasors affecting the FBS filter, respectively.

The single-phase impedances constituting the branches of FBS power filter are resonant cells, which could have several resonance frequencies. Connection of these resonant cells 


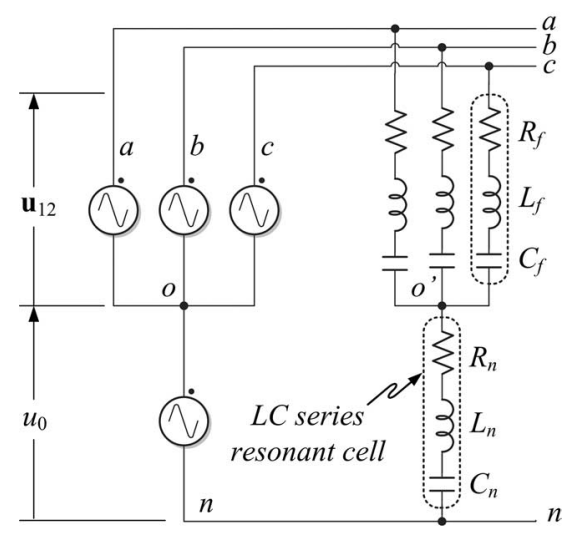

Fig. 2. FBS power filter based on simple series $L C$ resonant cells.

according to FBS topology gives rise to two groups of resonance frequencies, i.e., one group for the pn-seq components and another one for the z-seq components. This implies that the shunt passive power filter with FBS topology is able to perform selective filtering of current harmonics by setting up low-impedance paths to explicit current components with specific frequencies and sequences.

Even though the resonant cells composing the FBS filter branches can be really complex in some particular applications, a reasonably good filtering characteristic is obtained in practice when such resonant cells have a single resonance frequency. Simple $L C$ resonant cells will be considered in this introduction of the FBS power filter to simplify further explanations. A regular implementation of the FBS power filter based on simple series $L C$ resonant cells is presented in Fig. 2. In this case, the phase and neutral impedances, $Z_{f}$ and $Z_{n}$, are respectively given by

$$
\begin{aligned}
& \vec{Z}_{f}=R_{f}+j\left(L_{f} \omega-\frac{1}{C_{f} \omega}\right) \\
& \vec{Z}_{n}=R_{n}+j\left(L_{n} \omega-\frac{1}{C_{n} \omega}\right) .
\end{aligned}
$$

Both the pn-seq and the z-seq of the FBS network can be calculated by substituting (3) and (4) into (1) and (2), i.e.

$$
\begin{aligned}
\vec{Z}_{12} & =R_{f}+j\left(L_{f} \omega-\frac{1}{C_{f} \omega}\right) \\
\vec{Z}_{0} & =\left(R_{f}+3 R_{n}\right)+j\left[\left(L_{f}+3 L_{n}\right) \omega-\frac{1}{\omega}\left(\frac{1}{C_{f}}+\frac{3}{C_{n}}\right)\right] .
\end{aligned}
$$

Impedances of (5) and (6) evidence that the FBS filter of Fig. 2 has two resonance frequencies, namely, one for the pnseq components and another one for the z-seq components. Moreover, the following filtering parameters can be calculated from (5) and (6) for given values of $R, L$, and $C$ in the resonant cells:

1) $f_{12}$, the resonance frequency for pn-seq components;

2) $Q_{12}$, the quality factor for the pn-seq filter;

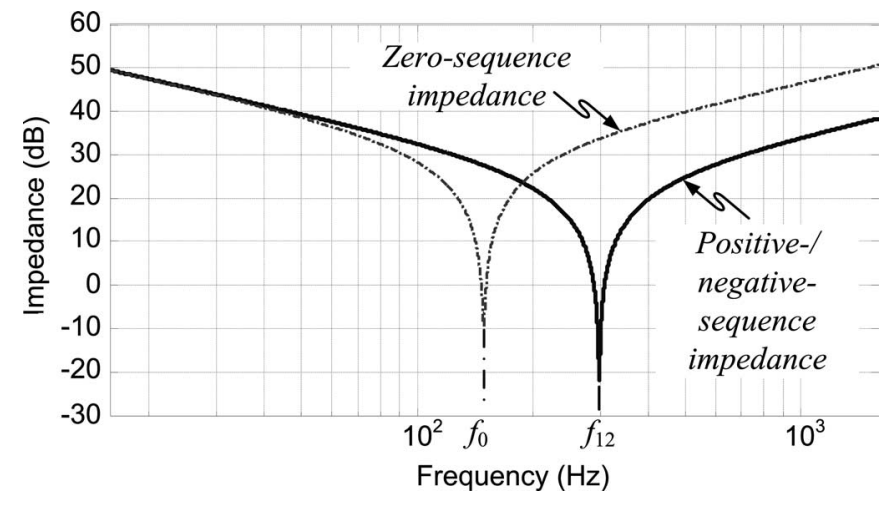

Fig. 3. Impedance variation FBS network.

3) $f_{0}$, the resonance frequency for z-seq components;

4) $Q_{0}$, the quality factor for the z-seq filter.

These parameters are determined by

$$
\begin{aligned}
f_{12} & =\frac{1}{2 \pi} \frac{1}{\sqrt{L_{f} C_{f}}} \quad Q_{12}=\frac{1}{R_{f}} \sqrt{\frac{L_{f}}{C_{f}}} \\
f_{0} & =\frac{1}{2 \pi} \frac{1}{\sqrt{\left(L_{f}+3 L_{n}\right)\left(\frac{C_{f} C_{n}}{C_{n}+3 C_{f}}\right)}} \\
Q_{0} & =\frac{1}{\left(R_{f}+3 R_{n}\right)} \sqrt{\frac{\left(L_{f}+3 L_{n}\right)\left(C_{n}+3 C_{f}\right)}{C_{f} C_{n}}} .
\end{aligned}
$$

Bode diagram of Fig. 3 shows evolution of the module of the FBS filter impedances of (5) and (6) as a function of the frequency. This diagram illustrates how the FBS network offers very low impedance to the pn-seq and z-seq current components at the resonance frequencies calculated by (7) and (8), respectively. Hence, the FBS topology presented in this paper is suitable for working as a shunt passive power filter, simultaneously draining off pn-seq current harmonics at frequency $f_{12}$ and z-seq current harmonics at frequency $f_{0}$.

It is worth to remark that currents drained by the pn-seq circuit and the z-seq circuit are independent. It is a useful characteristic in the case where the $z$-seq resonance frequency is set near to the fundamental grid frequency, e.g., $f_{0}=150 \mathrm{~Hz}$ for a $50-\mathrm{Hz}$ grid. Under such operating conditions, the z-seq circuit would absorb no current at fundamental frequency for a balanced grid voltage. It should also be pointed out that, for given values for $R_{f}$ and $R_{n}$ different from zero, impedance at the resonance frequency for the z-seq component is higher than for the pn-seq component. Hence, filtering capability of pn-seq circuit is comparatively higher than for z-seq one. As previously mentioned, the FBS power filter provides these filtering characteristics without using either transformers or special electromagnetic devices, which results in lower cost and higher modularity than in other existing commercial solutions [14]-[16].

\section{B. Variants of the FBS Passive Power Filter Implementation}

Several filter variants can be derived from the generic FBS filter structure of Fig. 2. Some of these particular structures of 
(a)

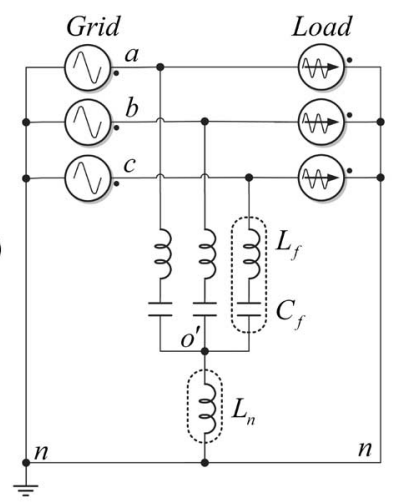

(b)

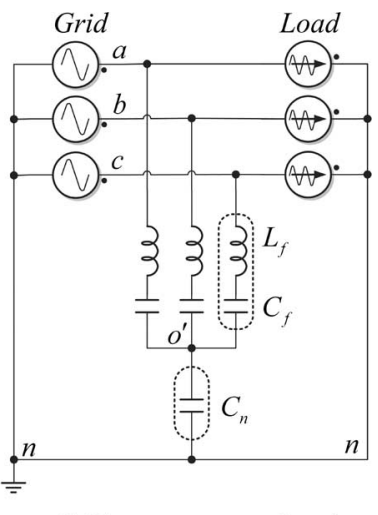

(c)

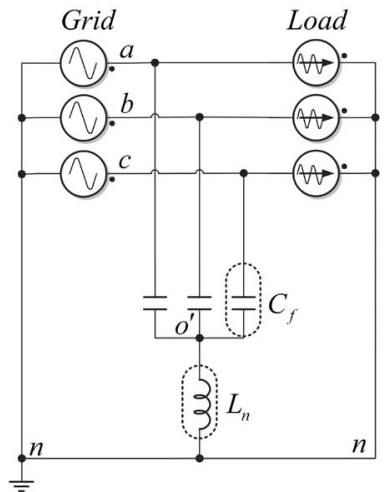

Fig. 4(b) shows another configuration of the FBS passive power filter suitable for those applications where the z-seq resonance frequency $f_{0}$ is higher than the pn-seq resonance frequency $f_{12}$. In this case, the phase branches are series $L C$ resonant cells, and the neutral branch is constituted by a capacitor $C_{n}$. Resonance frequencies and quality factors are given by

$$
\begin{aligned}
f_{12} & =\frac{1}{2 \pi} \frac{1}{\sqrt{L_{f} C_{f}}} \quad Q_{12}=\frac{1}{R_{f}} \sqrt{\frac{L_{f}}{C_{f}}} \\
f_{0} & =\frac{1}{2 \pi} \frac{1}{\sqrt{L_{f}\left(\frac{C_{f} C_{n}}{C_{n}+3 C_{f}}\right)}} \\
Q_{0} & =\frac{1}{\left(R_{f}+3 R_{n}\right)} \sqrt{\frac{L_{f}\left(C_{n}+3 C_{f}\right)}{C_{f} C_{n}}} .
\end{aligned}
$$

Fig. 4(c) shows a specific implementation of the FBS power filter destined to both compensation of reactive power at the fundamental grid frequency and cancellation of z-seq current harmonics at frequency $f_{0}$. In this case, phase branches are constituted by a capacitors bank, and the inductance is connected to the neutral branch. Z-seq resonance frequency and quality factor for the FBS power filter of Fig. 4(c) can be calculated by

$$
f_{0}=\frac{1}{2 \pi} \frac{1}{\sqrt{3 L_{n} C_{f}}} \quad Q_{0}=\sqrt{3} \frac{1}{R_{n}} \sqrt{\frac{L_{n}}{C_{f}}} .
$$

g. 4. Some specific implementations of the FBS power filter suitable for: (a) applications where $f_{0}<f_{12}$, (b) applications where $f_{0}>f_{12}$, (c) reactive power compensation and z-seq current harmonics cancellation, and (d) z-seq current harmonics cancellation.

the FBS power filter are shown in Fig. 4 and presented in the following. In these power filters, the number of freedom degrees for setting the resonance frequencies and quality factors is reduced in the pursuit of achieving a simpler and more economical implementation while at the same time keeping a satisfactory harmonic cancellation characteristic.

Fig. 4(a) shows a particular configuration of the FBS passive power filter suitable for those applications where the z-seq resonance frequency $f_{0}$ is lower than the pn-seq resonance frequency $f_{12}$. In this FBS implementation, the phase-branch impedances are constituted by series $L C$ resonant cells, and the neutralbranch impedance consists only of a single-phase inductance $L_{n}$. Resistances $R_{f}$ and $R_{n}$ have been intentionally omitted in Fig. 4 since they are not of interest for calculating the resonance frequencies. However, they should be considered for calculating the quality factor for each of the sequence components. Resonance frequencies and quality factors for the FBS power filter of Fig. 4(a) are given by

$$
\begin{aligned}
f_{12} & =\frac{1}{2 \pi} \frac{1}{\sqrt{L_{f} C_{f}}} \quad Q_{12}=\frac{1}{R_{f}} \sqrt{\frac{L_{f}}{C_{f}}} \\
f_{0} & =\frac{1}{2 \pi} \frac{1}{\sqrt{\left(L_{f}+3 L_{n}\right) C_{f}}} \\
Q_{0} & =\frac{1}{\left(R_{f}+3 R_{n}\right)} \sqrt{\frac{\left(L_{f}+3 L_{n}\right)}{C_{f}}}
\end{aligned}
$$

Fig. 4(d) shows a dual implementation to one that is shown in Fig. 4(c). In this case, the phase branches consist of three single-phase inductances, and the neutral branch is constituted by a single capacitor. Z-seq resonance frequency and quality factor for the FBS power filter of Fig. 4(d) can be calculated by

$$
f_{0}=\frac{1}{2 \pi} \frac{1}{\sqrt{(1 / 3) L_{f} C_{n}}} \quad Q_{0}=\sqrt{3} \frac{1}{R_{f}} \sqrt{\frac{L_{f}}{C_{n}}} .
$$

The neutral-branch impedance in all proposed structures could be substituted by an $L C$ resonant cell in order to reduce constraints in setting the resonance frequencies and the quality factors of the FBS power filter. Likewise, resonant cells in phases and neutral branches could be constituted by more complex networks to obtain multiple resonance frequencies using only one FBS power filter.

\section{FBS HYBRID POWER FILTER}

\section{A. General Description of the FBS Hybrid Power Filter}

A previously presented FBS passive power filter can offer a fairly good behavior when applied to cancel out current harmonics in three-phase four-wire systems under optimal operating conditions. However, the filtering characteristic of the FBS passive power filter is affected by typical problems of any passive filter, i.e., its filtering capability depends on the value of the grid impedance; when there exists risk of resonance, retuning is necessary due to ageing and tolerances.

A solution to overcome drawbacks associated with passive filters consists of integrating a power converter into the filter structure. This filtering system is known as a hybrid power 


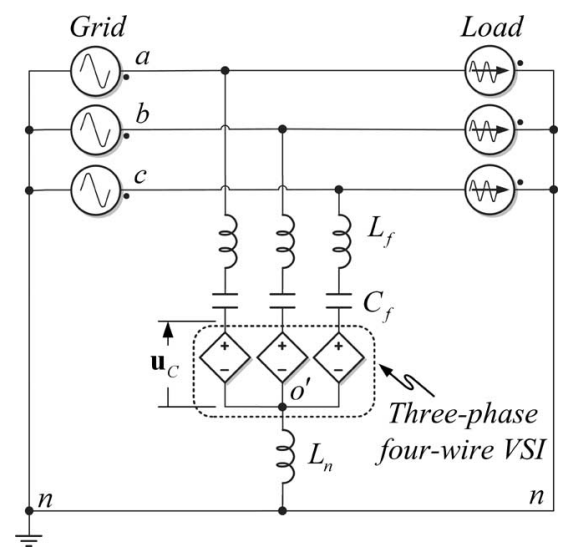

Fig. 5. Specific implementation of a three-phase four-wire FBS hybrid power filter.

filters [17]. A properly designed and well-controlled power converter can generate any voltage-current relationship at its output, obviously provided that it works inside its operative range. Therefore, such power converter could be understood as a "virtual impedance" integrated into the original structure of the passive filter. This virtual impedance improves the behavior of the original passive filter by increasing its capability for draining off current harmonics at frequencies different from the resonance ones, compensating drifts in the passive filter parameters, and damping oscillations due to resonance phenomena. Conventional three-phase three-wire hybrid filters are used to integrate a three-leg full-bridge voltage-source inverter (VSI) (without neutral connection) to improve the filter characteristic for pn-seq current harmonics.

\section{B. Specific Three-Phase Four-Wire Implementation of the FBS Hybrid Power Filter}

Different implementations of FBS hybrid power filters can be achieved depending on both the complexity of the branch impedances and the topology of the VSI. Fig. 5 shows a specific implementation of a three-phase four-wire FBS hybrid power filter that results from integrating a four-terminal VSI (four-leg, three-leg with neutral connection, three single-phase wye connected with neutral connection) into the FBS passive power filter structure shown in Fig. 2. The phase branches are constituted by $L C$ resonant cells, and the neutral branch is constituted by an inductor. Resonance frequencies $f_{12}$ and $f_{0}$ for the pn-seq and z-seq are given by (9) and (10), respectively. Resistances of the branches have been intentionally omitted in Fig. 5 to simplify the diagram.

The VSI of Fig. 5 can simultaneously synthesize both pn-seq and z-seq voltages at its output that makes it suitable for improving both the pn-seq and the z-seq passive filter characteristics at the same time.

Based on this fact, this paper proposes the FBS hybrid power filter of Fig. 5 as an effective solution for canceling out the most characteristic pn-seq current harmonics, i.e., the 5th, 7th-, and 11th-order harmonics, together with the z-seq third-order current harmonic. It is worth noting that the higher the voltage

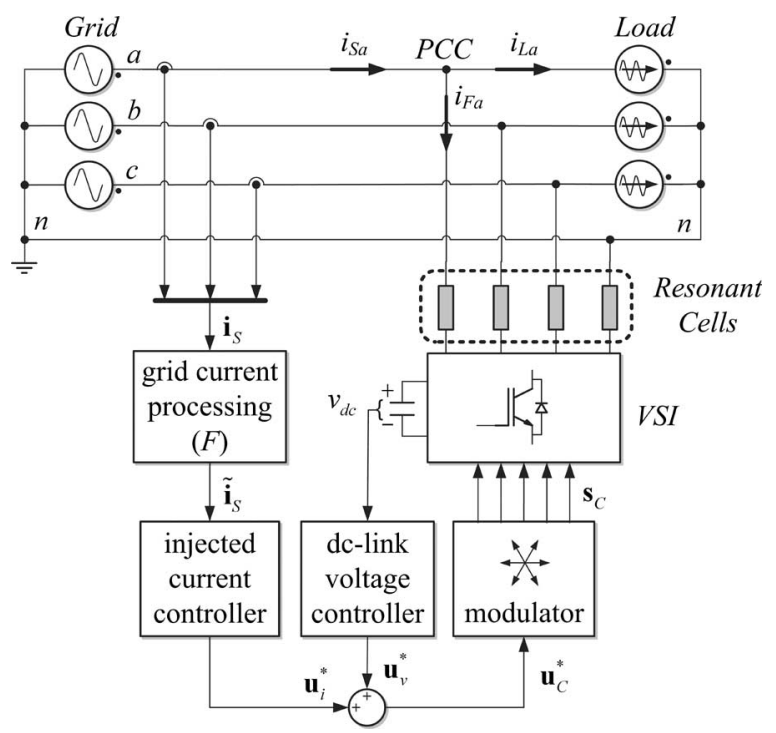

Fig. 6. Control diagram of the FBS hybrid power filter.

range for the VSI, the higher the controllability and the better the response of the FBS hybrid power filter, but the more expensive the implementation. It should also be highlighted that the power converter of the FBS hybrid power filter is generally much smaller and inexpensive than the power converter of a conventional active power filter. This is mainly due to the fact that the power converter in an FBS hybrid power filter ideally does not generate any voltage at fundamental frequency since the grid voltage at fundamental frequency drops across the capacitors of the $L C$ resonant cells. Therefore, this power converter is exclusively devoted to generate only those harmonic voltages that are necessary to inject the desired harmonic currents into the grid. Hence, the dc-link voltage of the power converter in an FBS hybrid power filter can be significantly reduced in relation to the conventional SAPF-around 90\% lower [18]. It should also be naturally understood that the performance of the FBS hybrid power filter is also directly related to the implemented control algorithm. Even though this paper aims only to present the main characteristics of the FBS topology, some key ideas about the control of the FBS hybrid power filter are pointed out in Section IV.

\section{BRIEF DESCRIPTION OF THE CONTROL SySTEM OF AN FBS HYBRID POWER FILTER}

The control system of the FBS hybrid power filter is constituted by the four main blocks shown in Fig. 6, namely: 1) the grid current processing block $(F)$, which is in-charge of selecting current harmonics to be filtered $\left(\tilde{\mathbf{i}}_{S}\right)$ from the controlled grid current $\left.\left(\mathbf{i}_{S}\right) ; 2\right)$ the injected current controller, which sets a reference voltage for the VSI $\left(\mathbf{u}_{i}^{*}\right)$ in order to cancel out the selected current harmonics; 3) the dc-link voltage controller, which modifies the original reference voltage of the VSI by adding an extra term $\left(\mathbf{u}_{v}^{*}\right)$ in order to keep the dc-link voltage at its nominal value; and 4) the modulator, which generates the switching signals of the VSI $\left(\mathbf{s}_{C}\right)$ from the final reference voltage of the VSI $\left(\mathbf{u}_{C}^{*}\right)$. 
The resonant cells of the FBS hybrid power filter of Fig. 6 offers very low impedance to pn-seq and z-seq currents at the tuning frequencies $f_{12}$ and $f_{0}$, respectively. Therefore, a low dclink voltage — only about $10 \%$ of the grid voltage—is necessary in the VSI to inject into the grid significant levels of harmonic currents at frequencies $f_{12}$ and $f_{0}$. However, impedance offered by the resonant circuits grows as frequency goes far away from the resonance ones. As a positive consequence, the current ripple injected by the FBS hybrid power filter into the grid at the switching frequency is very low. However, this also implies that the FBS hybrid power filter can only compensate a limited range of the pn-seq and z-seq current harmonics. For this reason, the grid current processing block $(F)$ extracts those individual frequencies that are suitable to be filtered $\left(\tilde{\mathbf{i}}_{S}\right)$ from the grid current $\left(\mathbf{i}_{S}\right)$ by using any signal filtering technique. As previously mentioned, the harmonics compensation range can be extended by increasing the dc-link voltage level, which increases the VSI rating, and consequently, its cost.

Currents signals at the input of the current processing block can be sensed either upstream or downstream of the point of common coupling (PCC) between the FBS power filter and the grid. The transfer function of the control system depends on both the current sensing point and the type of injected current controller. This current controller can work on either synchronous or static reference frames using either conventional synchronous PI or stationary resonant controllers, respectively [19], [20]. The dc-link voltage controller generates a reference voltage inphase with the current at the fundamental grid frequency flowing through the VSI. Interaction of both voltage and current generates an exchange of active power between VSI and the grid intended to keep the energy stored into the dc-link stored energy — and so the dc-link voltage-close to its nominal value.

Since the aim of this paper is to only introduce the FBS topology and some of its main applications, the control diagram of Fig. 6 is implemented by using light algorithms, as described hereafter. Hence, the grid current processing block $(F)$ consists off three very narrow notch filters (NFs) - one per phase-canceling out the fundamental frequency component from the current harmonics to be compensated by the filter. The injected current controller was implemented by a simple proportional regulator per phase. The control law of the equivalent control diagram shown in Fig. 7(a) is given by

$$
\mathbf{u}_{C}^{*}=Z_{V} \cdot \mathbf{i}_{S} \quad Z_{V}=\mu k F
$$

where $\mu$ is the gain of the VSI. A straightforward analysis of the diagram shown in Fig. 7(a) conducts to the following transfer function:

$$
\mathbf{i}_{S}=\frac{1}{Z_{F}+Z_{S}+Z_{V}}\left(\mathbf{i}_{L} Z_{F}+\mathbf{u}_{S}\right) .
$$

Transfer function of (16) is a general function, which can be applied to analyze the frequency response of the FBS hybrid filter for both pn-seq and z-seq current harmonics components. Impedance expression to be substituted in (16) when the frequency analysis is performed for either pn-seq or z-seq



(a)

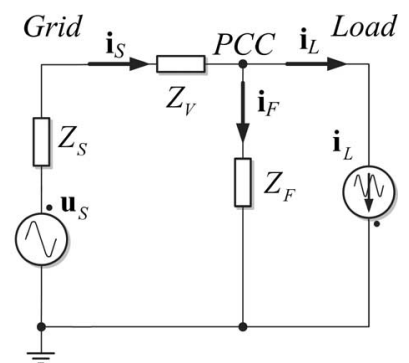

(b)
Fig. 7. (a) Simple control diagram of the FBS hybrid power filter. (b) Equivalent circuit with a virtual impedance resulting form the control law.

components are, respectively, is given by

$$
\begin{aligned}
& \vec{Z}_{F}=\vec{Z}_{12}=R_{f}+j\left(L_{f} \omega+\frac{1}{C_{f} \omega}\right) \quad \text { or } \\
& \vec{Z}_{F}=\vec{Z}_{0}=\left(R_{f}+3 R_{n}\right)+j\left[\left(L_{f}+3 L_{n}\right) \omega-\frac{1}{C_{f} \omega}\right] .
\end{aligned}
$$

The grid impedance is given by

$$
\vec{Z}_{S}=R_{S}+j L_{S} \omega
$$

where $R_{S}$ and $L_{S}$ are the resistance and inductance presented by the grid, respectively.

Transfer function of (16) reveals that integration of a VSI controlled by the control law of (15) into the FBS hybrid filter structure is equivalent to inserting a virtual impedance $Z_{V}$ upstream of the PCC between the hybrid power filter and the grid. Fig. 7(b) shows the resultant equivalent circuit including the virtual impedance $Z_{V}$. This virtual impedance increases the capability of the hybrid power filter for canceling out the load-side harmonics, isolates the hybrid power filter from the grid-side current harmonics, and reduces the risk of resonance between the resonant cells and the grid impedance [21]. The control law proposed in this paper is intentionally simple; however, it can be improved by implementing an enhanced controller consisting of individual regulators with a different gain for each of the current harmonics to be compensated [22].

\section{Performance Study of the Three-Phase Four-Wire FBS HYBRID POWER FILTER}

The implementation of the three-phase four-wire FBS hybrid power filter is shown in Fig. 8. To evaluate the performance of the proposed hybrid power filter, three single-phase diode rectifiers injecting current harmonics at the load side $\left(\mathbf{i}_{L}\right)$ are considered. In this particular implementation, a conventional three-leg full-bridge VSI with the negative rail of the dc-bus connected to the neutral conductor is used for injecting both pn-seq and z-seq currents into the three-phase four-wire grid. This interesting VSI topology was applied in [23] to a conventional three-phase four-wire hybrid power filter with only one common resonance frequency for both the pn-seq and the z-seq components. In that work, however, a too high and costly dc-link voltage had to be used for controlling the current injected into 


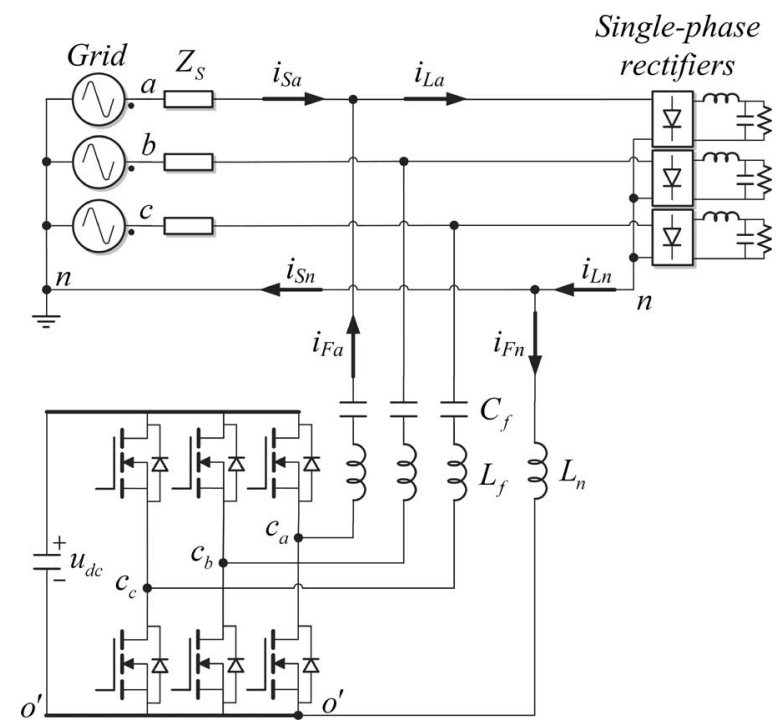

Fig. 8. Three-phase four-wire FBS hybrid power filter.

the grid $\left(500 \mathrm{~V}_{\mathrm{dc}}\right.$ for $400 \mathrm{~V}_{\mathrm{ac}}$ mains). The FBS hybrid power filter presented in this paper overcomes this drawback due to its two independent resonance frequencies-one for pn-seq and another one for z-seq components-which allows controlling currents with both sequences using a low dc-link voltage level (about $50 \mathrm{~V}_{\mathrm{dc}}$ for $400 \mathrm{~V}_{\mathrm{ac}}$ mains). Even though implementation of the FBS hybrid power filter shown in Fig. 8 is very attractive in terms of simplicity and economy, it is acknowledged that any other four-terminal VSI topology could be used as well.

The output voltage of the VSI of Fig. 8, referenced to the negative dc-bus rail, is formed by both ac and dc components, i.e.

$$
u_{C i o^{\prime}}=\bar{u}_{C i o^{\prime}}+\tilde{u}_{C i o^{\prime}} \quad \text { with } i \in\{a, b, c\} .
$$

The dc voltage component $\bar{u}_{C i o^{\prime}}$, equal to $u_{\mathrm{dc}} / 2$, is blocked by the capacitors $C_{f}$ of the resonant cell, and so, it does not inject any dc current into the grid. The ac voltage component $\tilde{u}_{C i o^{\prime}}$ has a maximum range of $\pm u_{\mathrm{dc}} / 2$ for injecting the ac compensation currents into the grid. Therefore, the gain of the VSI of Fig. 8 is given by $\mu=u_{\mathrm{dc}} / 2$.

Fig. 9 shows the simple control system designed to drive the three-phase four-wire FBS hybrid filter, which is the subject of study in this paper. Three fourth-order NFs, one per phase, with a center frequency of $50 \mathrm{~Hz}$ and a bandwidth of $5 \mathrm{~Hz}$ act as the grid current processing block extracting the current harmonics to be compensated $\tilde{\mathbf{i}}_{S}$. A proportional per phase regulator with gain $k=2.5$ constitutes the injected current controller. The dclink voltage control is performed by a PI regulator with a rather low bandwidth $\left(k_{p}=10\right.$ and $\left.\tau_{i}=1 \mathrm{~s}\right)$. This regulator sets a proportionality coefficient $k_{\mathrm{dc}}$ between the fundamental frequency current flowing through the FBS filter $\mathbf{i}_{F 1}$ and the fundamental frequency voltage at the output of the VSI. A fourth-order bandpass filter (BPF) with a center frequency of $50 \mathrm{~Hz}$ and a bandwidth of $5 \mathrm{~Hz}$ is used to extract the current $\mathbf{i}_{F 1}$.

Two different values of grid impedance are considered in simulation in order to evaluate the effectiveness of the proposed

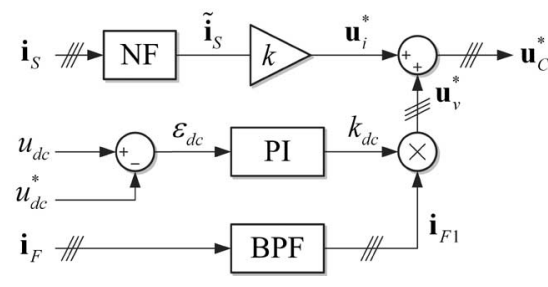

Fig. 9. Control of the three-phase four-wire implementation of the FBS hybrid power filter.

TABLE I

GRID PARAMETERS IN THE Two STUDY CASES

\begin{tabular}{ccccc}
\hline & Nominal & Line & Line & Line \\
Study Case & power & voltage & $\begin{array}{c}\text { resistance } \\
\text { inductance }\end{array}$ \\
& & & $(1.5 \%)$ & $(6.25 \%)$ \\
\hline A (weak PCC) & $10 \mathrm{~kW}$ & $400 \mathrm{~V}$ & $240 \mathrm{~m} \Omega$ & $3,2 \mathrm{mH}$ \\
B (strong PCC) & $100 \mathrm{~kW}$ & $400 \mathrm{~V}$ & $24 \mathrm{~m} \Omega$ & $0,32 \mathrm{mH}$ \\
\hline
\end{tabular}

TABLE II

PARAMETERS OF THE FBS HYBRID POWER FILTER

\begin{tabular}{cc}
\hline Parameter & Value \\
\hline Filter phase-branch inductance $\left(L_{f}\right)$ & $8.5 \mathrm{mH}$ \\
Filter phase-branch resistance $\left(R_{f}\right)$ & $244 \mathrm{~m} \Omega$ \\
Filter phase-branch capacitance $\left(C_{f}\right)$ & $33.5 \mu \mathrm{F}$ \\
Filter neutral-branch inductance $\left(L_{n}\right)$ & $8.5 \mathrm{mH}$ \\
Filter neutral-branch resistance $\left(R_{n}\right)$ & $244 \mathrm{~m} \Omega$ \\
Nominal dc-link voltage $\left(U_{d c}\right)$ & $45 \mathrm{~V}$ \\
Dc-link capacitor $\left(C_{d c}\right)$ & $14100 \mu \mathrm{F}$ \\
Switching frequency $\left(f_{S W}\right)$ & $14.4 \mathrm{kHz}$ \\
\hline
\end{tabular}

three-phase four-wire FBS topology under different connection conditions-one value is referred to as "weak PCC" and the other as "strong PCC." Grid parameters for both study cases are given in Table I.

Whatever be the value of the grid impedance from Table I, the three single-phase rectifiers of Fig. 8 consume $2.5 \mathrm{~kW}$ of power, demand a phase current $i_{L a}$ with an rms value of $4.1 \mathrm{~A}$ and a total harmonic distortion (THD) $=43.5 \%$, and inject third-harmonic sinusoidal current in the neutral conductor with an rms value of $4.9 \mathrm{~A}$. Table II shows the main parameters of the three-phase four-wire FBS power filter. Applying (9) and (10) to this set of parameters, resonance frequencies for the pnseq and z-seq components are $f_{12}=300 \mathrm{~Hz}$ and $f_{0}=150 \mathrm{~Hz}$, respectively. Capacitive reactive power supplied by the resonant cells is $Q_{F}=1.64 \mathrm{kvar}$ for a $400 \mathrm{~V} / 50 \mathrm{~Hz}$ grid.

The FBS hybrid filter of Fig. 8 is evaluated under two different operation modes, namely the passive and the hybrid mode. In the passive mode, the $\mathbf{i}_{S}$ input of the control system of Fig. 9 is forced to zero, and consequently, the reference voltage $\mathbf{u}_{i}^{*}$ is zero as well. Hence, the VSI does not contribute to the filtering action. The virtual impedance $Z_{V}$ of (16) should be considered equal to zero in the passive mode. In the hybrid mode, the FBS 
(a)



(b)

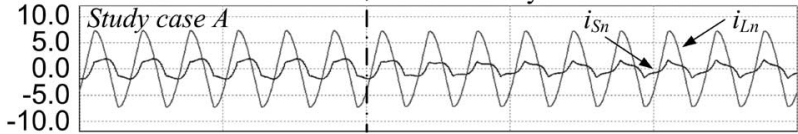

(c)

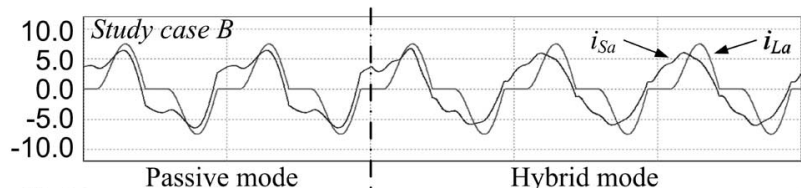

(d)

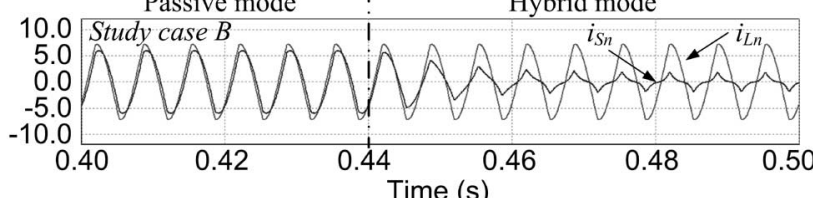

Fig. 10. Simulated load and grid currents resulting from the action of a threephase four-wire FBS hybrid power filter. (a) Phase currents in a weak grid. (b) Neutral currents in a weak grid. (c) Phase currents in a strong grid. (d) Neutral currents in a strong grid.

power filter controller of Fig. 9 provides the proper reference voltage $\mathbf{u}_{i}^{*}$ to the VSI in order to cancel out pn-seq and z-seq current harmonics at the grid side.

From all previous settings, Fig. 10 shows the simulation results of the three-phase four-wire FBS power filter of Fig. 8. The FBS filter works in the passive mode until $t=0.44 \mathrm{~s}$ when the active mode starts. Fig. 10(a) and (b), respectively, show the currents in the phase $a$ and in the neutral conductor for the study case A (weak PCC). In the passive mode, the FBS filter should be draining off the $\mathrm{z}$-seq third harmonic and attenuating the pnseq fifth and seventh harmonics since $f_{0}=150 \mathrm{~Hz}$ and $f_{12}=$ $300 \mathrm{~Hz}$. However, Fig. 10(a) shows that the fifth harmonic is not attenuated but amplified at the source side as a consequence of a parallel resonance phenomenon that occurred between the FBS power filter and the grid impedance. Based on (16), Fig. 11 shows the frequency response of the FBS power filter in the presence of both z-seq and pn-seq current harmonics at the load side. In Fig. 11, the relationship between $i_{S}$ and $i_{L}$ when the FBS filter works in the passive mode is represented by dashed lines. Two resonance peaks are identified in the passive mode, one for z-seq components at $141 \mathrm{~Hz}$ and another one for pnseq components at $254 \mathrm{~Hz}$. This second peak justifies the high level of fifth harmonic in $i_{S}$ when the resonance phenomenon is excited by the fifth-harmonic current injected by the load-side rectifiers. Nevertheless, the FBS power filter shows an acceptable filtering characteristic when working in the passive mode connected to a weak grid, even though the distortion generated by the resonance phenomenon is considered. Connection of the FBS power filter of Fig. 8, working in the passive mode, to a weak PCC gives rise to a THD $=24.3 \%$ for the phase current $i_{S a}$ and to an rms value of $1.48 \mathrm{~A}$ for the neutral current $i_{S n}$.

The FBS filter works in the hybrid mode from $t=0.44 \mathrm{~s}$, and its filtering characteristic is improved. The resonance at the fifth harmonic is canceled and the harmonic content in the grid cur-

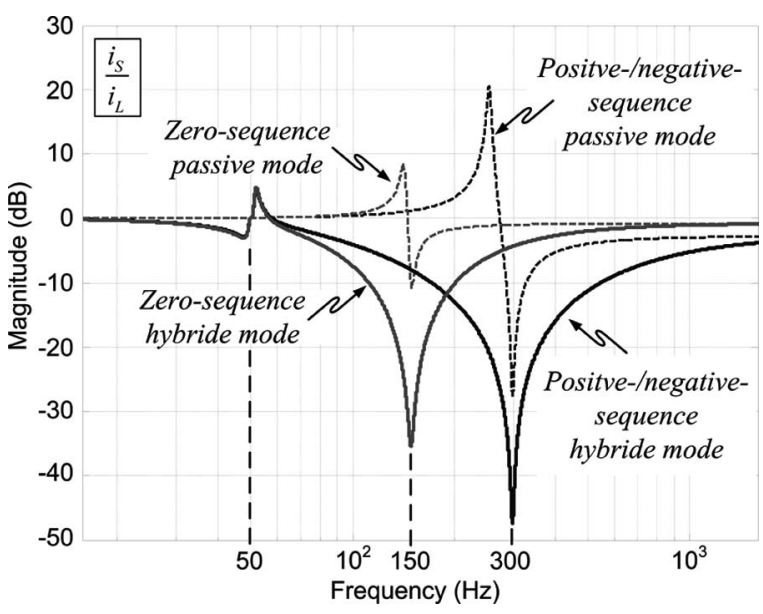

Fig. 11. Frequency response of the three-phase four-wire FBS power filter.

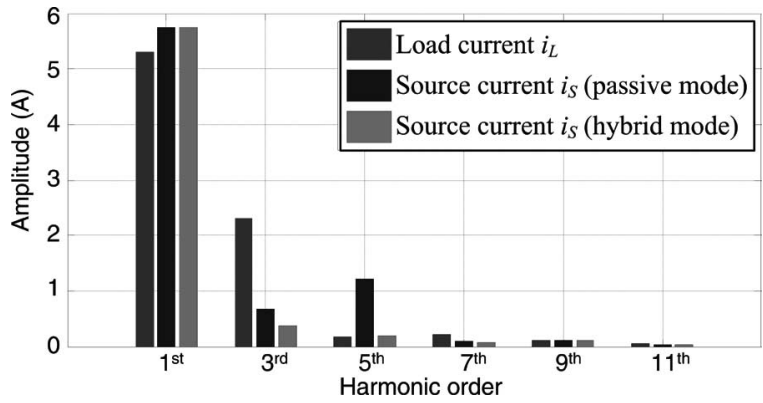

Fig. 12. Current spectrum of the load and source current when a weak PCC is considered.

rent is further reduced. Once steady-state conditions are reached in the hybrid mode, the phase current $i_{S a}$ has a THD of $7.3 \%$ and the neutral current $i_{S n}$ has an rms value of $0.75 \mathrm{~A}$. Fig. 11 perfectly illustrates this improvement in the filter performance. The frequency response of the FBS filter when working in hybrid mode, represented by solid lines in Fig. 11, shows that the resonance peaks are canceled out, and the bandwidth of both the pn-seq and the z-seq filtering characteristics is enlarged. It is worth to comment that the small resonance peak at $51.8 \mathrm{~Hz}$ appears as a consequence of the high-quality factor set to the $\mathrm{NF}$, which constitutes the grid current processing block in this paper. A more accurate and frequency adaptive grid current processor could be achieved by using a phase-locked loop (PLL) based processing system [24]. Fig. 12 shows the harmonic spectrum of the phase currents $i_{S}$ and $i_{L}$. This spectrum graphically describes the FBS power filter performance when operating in both the passive and the hybrid modes connected to a weak PCC.

Fig. 10(c) and (d) shows phase and neutral currents for the study case B (strong PCC). In this case, considering the FBS power filter working in the passive mode, the resonance peak in the frequency response is given at a higher frequency (292 Hz) with the amplitude about ten times smaller than in the case of a weak grid, and thus, the resonance effects on $i_{s a}$ are almost imperceptibles. However, the filtering capability of the FBS power filter is rather reduced in this case because of the 
TABLE III

CURRENT REPRESENTATIVE VALUES FOR THE DifFERENT OPERATION MODES AND PCC POWERS

\begin{tabular}{ccccccc}
\hline \hline \multirow{2}{*}{$\begin{array}{c}\text { Characteristic } \\
\text { value }\end{array}$} & \multicolumn{3}{c}{$\begin{array}{c}\text { Study case A } \\
\text { (weak grid) }\end{array}$} & \multicolumn{3}{c}{$\begin{array}{c}\text { Study case B } \\
\text { (strong grid) }\end{array}$} \\
\cline { 2 - 7 } & Passive & Hybrid & Ideal & Passive & Hybrid & Ideal \\
\hline $\operatorname{THD}\left(i_{S a}\right)[\%]$ & 24.3 & 7.3 & 5.5 & 35.2 & 8.5 & 5.9 \\
$\operatorname{THD}\left(i_{L a}\right)[\%]$ & 43.4 & 43.5 & 43.5 & 43.4 & 43.4 & 43.4 \\
$\operatorname{rms}\left(i_{s n}\right)[\mathrm{A}]$ & 1.48 & 0.75 & 0.36 & 4.3 & 0.82 & 0.4 \\
$\operatorname{rms}\left(i_{L n}\right)[\mathrm{A}]$ & 4.9 & 4.9 & 4.9 & 4.9 & 4.9 & 4.9 \\
\hline \hline
\end{tabular}

low value of the grid impedance. The phase current $i_{S a}$ roughly results from addition of the current demanded by the load-side rectifiers $i_{L a}$ to the sinusoidal reactive current demanded by the resonant cells of the FBS filter, which gives rise to a rather distorted source current. Likewise, $i_{S n}$ is almost equal to $i_{L n}$ when the FBS filter operates in the passive mode connected to a strong PCC. The performance of the passive power filter in this case is poor, with a THD $=35.2 \%$ for $i_{S a}$ and an rms value of $4.3 \mathrm{~A}$ for $i_{S n}$. The quality of the source currents is enhanced when the FBS power filter works in the hybrid mode. The grid impedance is increased by virtual impedance $Z_{v}$, and the phase and neutral currents now look like those obtained from the FBS hybrid filter when a weak PCC was considered. In this case, $i_{S a}$ has a THD $=8.5 \%$ and $i_{S n}$ has an rms value of $0.82 \mathrm{~A}$.

It is worth to remark that the simulation results presented in this section are based on realistic values for the reactors and capacitors constituting the resonant cells. The FBS filter performance would be improved if idealized components where considered. Table III collects all the representative values of $i_{S a}$ and $i_{S n}$ presented earlier in this section for different operation modes and PCC powers. The column called "Ideal" shows the results obtained when no resistors are considered in the resonant cells of the FBS power filter working in the hybrid mode.

\section{EXPERIMENTAL RESULTS}

An experimental prototype was built to validate performances of the three-phase four-wire FBS hybrid power filter of Fig. 8. MOSFET devices IRF540N $100 \mathrm{~V} / 33$ A were used to implement the VSI. MOSFET switches are very suitable for this kind of LV/low-current applications because of their low ON-resistance, low switching time, low power losses, and low cost. For LV applications in the range of $300 \mathrm{~A}$ and further, modern LV insulated gate bipolar transistors (IGBTs) might be considered as a better choice to implement the VSI due to their low ONstate voltage, relatively fast switching, and low prices. As the voltage grows up, IGBTs are the most competitive solution. The light control algorithm of Fig. 9 is programmed into a lowcost 16-bit fixed-point DSP dsPIC30F6010 running at 30 MIPS. The rest of parameters of the experimental prototype matched to those used in simulation, some of them listed in Tables I and II.

Fig. 13 shows representative records of measured currents in the experimental prototype. In these scopes, a dash-dot line

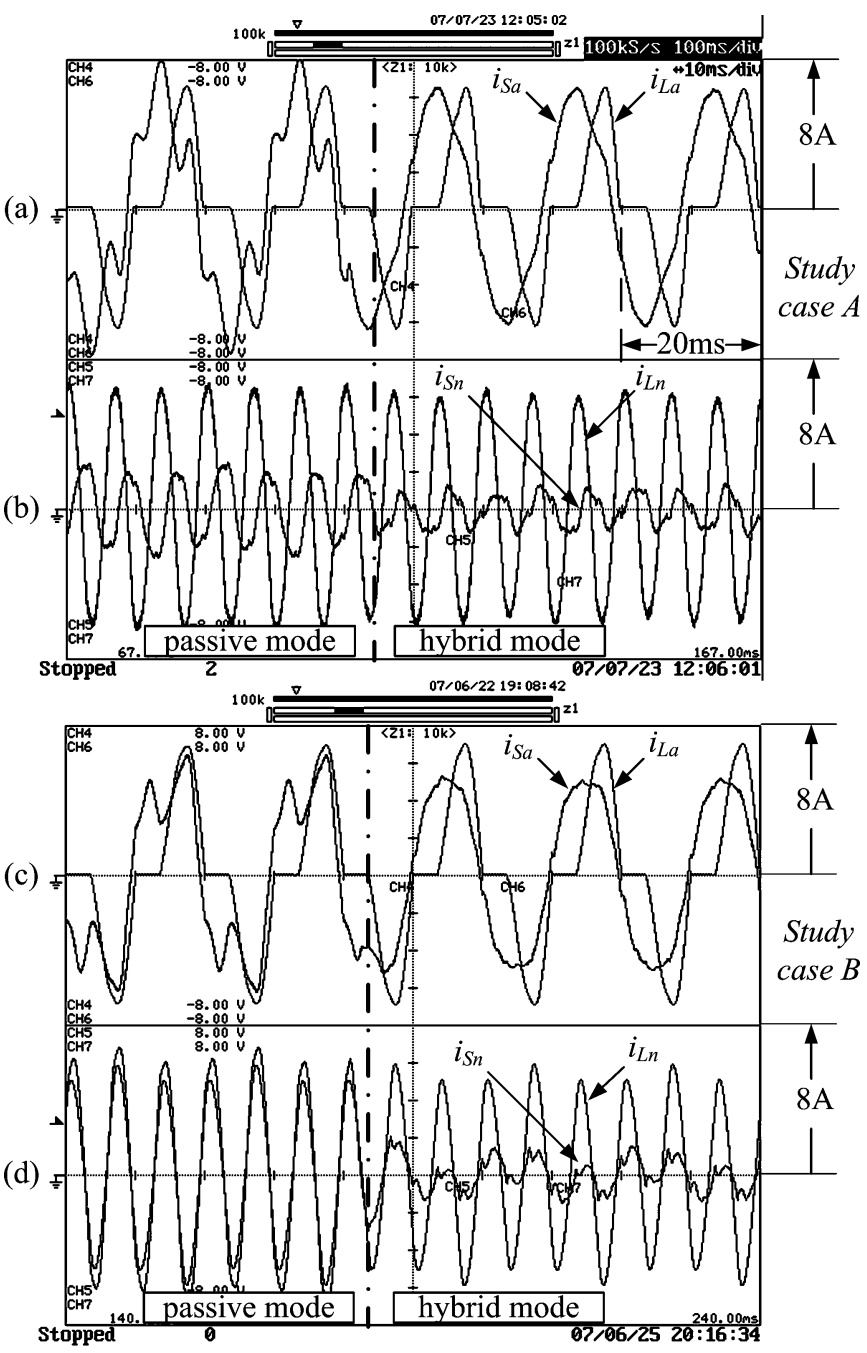

Fig. 13. Experimental source and load currents waveforms for the three-phase four-wire FBS hybrid power filter. (a) Grid current in a weak grid. (b) Neutral current in a weak grid. (c) Grid current in a strong grid. (d) Neutral current in a strong grid.

indicates the transition time from the passive to the hybrid operating mode. Fig. 13(a) and (b), respectively, shows current in the phase $a$ and in the neutral conductor when the load was supplied by a weak $10 \mathrm{~kW}$ ac source. These waveforms are fairly similar to those obtained by simulation and shown in Fig. 10. However, the current distortion due to the parallel resonance between the FBS filter and the grid at the fifth harmonic was even higher in the experimental setup than in simulation. The neutral current $i_{s n}$ presented similar levels to those obtained in simulation, and the small difference could be due to both tolerances in the filter components and precision errors in the control algorithm.

Fig. 13(c) and (d) shows line and neutral currents from a second experiment in which the load was supplied by an electrical connection with a nominal power of $100 \mathrm{~kW}$. The experimental results are again so similar to those obtained by simulation. In this experiment, however, the current $i_{S n}$ presents a small oscillation at the fundamental frequency. It is due to the fact that load currents demanded by the three load-side rectifiers were 


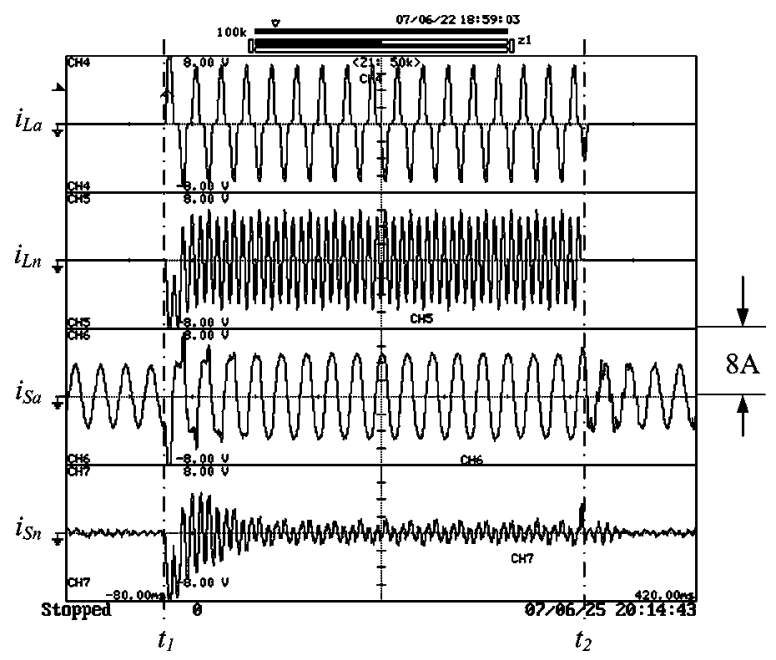

Fig. 14. Dynamic response of the three-phase four-wire FBS hybrid filter.

slightly unbalanced in the experimental setup. Consequently, a small current at the fundamental frequency was injected by the load rectifiers into the neutral conductor. Such current component can be seen in Fig. 13(d) as a small oscillation at $50 \mathrm{~Hz}$ enclosing the neutral current $i_{L n}$, which is mainly constituted by a $300-\mathrm{Hz}$ component. As previously justified, such current at the fundamental frequency cannot be canceled by the FBS hybrid power filter, and is thus propagated toward the source-side neutral current $i_{S n}$.

Fig. 14 shows the dynamic response of the three-phase fourwire FBS power filter when working in the hybrid mode connected to a weak PCC. Before $t=t_{1}$, the load rectifiers are disconnected; for this reason, the filter only supplies reactive power at the fundamental frequency to the grid. The phase current $i_{S a}$ is sinusoidal with an rms value of $2.6 \mathrm{~A}$, and $i_{S n}$ is almost equal to zero. The load-side rectifiers are connected at $t=t_{1}$. The FBS hybrid power filter again achieves almost sinusoidal waveforms in $i_{S a}$ after three grid cycles from the load connection. There are not remarkable peaks in $i_{S a}$ and $i_{S n}$ during the transient stabilization period of the source-side current. A similar behavior is found when the load rectifiers are disconnected at $t=t_{2}$.

\section{CONCLUSION}

A new filter based on the FBS topology was presented in this paper. Analysis, simulations, and experiments conducted in this paper proved the FBS power filter topology as an effective and economical solution for current conditioning in three-phase four-wire networks. Connection of resonant cells according to FBS topology results in independent low-impedance paths for both pn- and z-seq components at specific frequencies, which allows performing selective filtering of current harmonics in both the phases and the neutral conductor of a three-phase four-wire system. The FBS power filter topology can operate in either passive or hybrid mode. In this second mode, a very simple VSI - with a dc-link voltage around $10 \%$ of the grid line voltage-extends further filtering capability of the passive network as well as it avoids overloads and unexpected resonances. A three-phase four-wire hybrid power filter was presented in this paper as an attractive application of the FBS filtering topology. The proposed solution allows lowcost implementation of the neutral current conditioning functionality in a conventional wye-connected three-phase passive filter.

The proposed hybrid filter needs more passive components than a conventional SAPF. However, it is worth mentioning that, for a given current to be driven by the power converter, and for an equivalent switching frequency and current ripple injected into the grid, the inductors of the $L C$ resonant cells of an FBS hybrid power filter tuned at the seventh harmonic have almost the same value than the link inductors of an SAPF. The value of the inductor used in the FBS hybrid power filter will grow with respect to the one used in a conventional SAPF as the tuning frequency of the resonant cells decreases. Nevertheless, the tuning frequency will be typically around the sixth/seventh harmonics since the two most important currents harmonics to be canceled are usually the fifth and the seventh ones. The capacitors used in the $L C$ resonant cells of the FBS hybrid power filter are much more expensive than the small capacitors used in a SAPF for filtering the switching frequency. This increment in the cost of the capacitors is so far compensated by the reduction in the cost of the VSI inverter used in the FBS hybrid power filter with respect to the conventional SAPF. As a conclusion, the overall cost of the FBS hybrid power filter is generally lower than the cost a conventional SAPF for a given rated current. It is particularly true when the FBS hybrid power filter is applied to MV distribution power lines. As an example, a conventional two-level VSI based on regular IGBTs with a dc-bus voltage of $1500 \mathrm{~V}$ can drive a FBS hybrid power filter working on a MV line of $12 \mathrm{kV}$. Obviously, this VSI is cheaper than the advanced multilevel power converter to be used if a conventional SAPF structure was implemented.

Even though the proposed FBS hybrid power filter presents a narrower filtering band than in the case of a conventional SAPF, its performance makes it very suitable for conditioning most of the typical distorting loads at a lower price. For example, in the experimental prototype built in this paper (tuned at the sixth harmonic), the filtering band covers the 3rd (33\%), 5th $(45 \%), 7$ th $(45 \%), 11$ th $(11 \%)$, and 13th $(8 \%)$ harmonics, where percentages represent the phase current absorbed by the FBS hybrid power filter referred to its rated current.

A simple three-phase VSI and a light control algorithm were used in this paper to emphasize economy and simplicity of the proposed filtering solution. Simulations together with experimental evaluation were conducted in order to evaluate the performance of the presented three-phase four-wire hybrid power filter. Simulation and experimental results confirmed the good behavior of the proposed filtering solution in canceling out current harmonics in both the phase and the neutral conductor. Performance of the proposed filtering solution can be improved by using more complex resonant circuits with multiple resonance frequencies and/or designing independent controllers for each of the current harmonics to be filtered. The FBS filter concept is protected under the patent P200700209 [25]. 


\section{REFERENCES}

[1] IEEE Recommended Practices and Requirements for Harmonic Control in Electrical Power Systems. IEEE, IEEE Standard 519-1992, 1992.

[2] Electromagnetic Compatibility (EMC), Part 3: Limits, Section 2: Limits for Harmonics Current Emissions (Equipment Input Current $\leq 16 \mathrm{~A}$ Per Phase), IEC Standard 61000-3-2, 1997.

[3] Electromagnetic Compatibility (EMC), Part 3: Limits, Section 4: Limitation of Emissions of Harmonics Currents in Low-Voltage Power Supply Systems for Equipment with Rated Currents Greater Than 16A, IEC Standard 61000-3-4

[4] R. C. Dugan, M. F. McGranaghan, S. Santoso, and H. W. Beaty, Electrical Power Systems Quality, 2nd ed. New York: McGraw-Hill, 2002.

[5] J. C. Das, "Passive filters-Potentialities and limitations," IEEE Trans. Ind. App., vol. 40, no. 1, pp. 232-241, Jan./Feb. 2004.

[6] J. Arrillaga, D. A. Bradley, and P. S. Bodger, Power System Harmonics. New York: Wiley, 1985, pp. 304-306.

[7] B. Sing, K. Al-Haddad, and A. Chandra, "A review of active filters for power quality improvement," IEEE Trans. Ind. Electron., vol. 46, no. 5, pp. 960-971, Oct. 1999.

[8] R. Inzunza and H. Akagi, "A 6.6-kV transformerless shunt hybrid active filter for installation on a power distribution system," IEEE Trans. Power Electron., vol. 20, no. 4, pp. 893-900, Jul. 2005.

[9] S. Bhattacharya, D. Divan, and P. Cheng, "Hybrid solutions for improving passive filter performance in high power applications," IEEE Trans. Ind. Appl., vol. 33, no. 3, pp. 732-747, May/Jun. 1997.

[10] H. Akagi, S. Srianthumrong, and Y. Tamai, "Comparisons in circuit configuration and filtering performance between hybrid and pure shunt active filters," in Proc. IEEE Ind. Appl. Soc. Conf., 2003, pp. 1195-1202.

[11] S. Kim, "Active zero-sequence cancellation technique in unbalanced commercial building power system," in Proc. IEEE Appl. Power Electron. Conf. Exp. (APEC 2004), pp. 185-190.

[12] F. Z. Peng and G. J. Su, "A series LC filter for harmonic compensation of ac drives," in Proc. IEEE Power Electr. Spec. Conf. (PESC 1999), pp. 213-218.

[13] F. Z. Peng, "Harmonic sources and filtering approaches," IEEE Trans. Ind. App., vol. 7, no. 4, pp. 18-25, Jul./Aug. 2001.

[14] "Active harmonic power filter apparatus and method," U.S. Patent US5 568 371, Oct. 221996.

[15] "Active neutral current compensator," U.S. Patent US5 574 356, Nov. 12, 1996.

[16] "Passive power filter tunable at two simultaneous frequencies, one for zerosequence and another on for positive-sequence," (in Spanish), Spanish Patent ES2 253 095, Jan. 7, 2007.

[17] D. Rivas, L. Moran, J. W. Dixon, and J. R. Espinoza, "Improving passive filter compensation performance with active techniques," IEEE Trans. Ind. Electron., vol. 50, no. 1, pp. 161-170, Feb. 2003.

[18] L. Asiminoaei, W. Wiechowski, F. Blaabjerg, B. Kedra, and T. Krzeszowiak, "A new control structure for hybrid power filter to reduce the inverter power rating," in Proc. IEEE Ind. Electron. Conf. (IECON 2006), pp. 2712-2717.

[19] M. Liserre, R. Teodorescu, and F. Blaabjerg, "Multiple harmonics control for three-phase grid converter systems with the use of PI-RES current controller in a rotating frame," IEEE Trans. Power Electron., vol. 21, no. 3, pp. 836-841, May 2006

[20] L. Asiminoaei, C. Lascu, F. Blaabjerg, and I. Boldea, "Performance improvement of shunt active power filters with dual parallel topology," IEEE Trans. Power Electron., vol. 22, no. 1, pp. 229-236, Jan. 2007.

[21] H. Fujita, T. Yamasaki, and H. Akagi, "A hybrid active filter for damping of harmonic resonance in industrial power systems," IEEE Trans. Power Electron., vol. 15, no. 2, pp. 215-222, Mar. 2000.

[22] D. Basic, V. S. Ramsden, and P. K. Muttik, "Harmonic filtering of highpower 12-pulse rectifier loads with a selective hybrid filter system," IEEE Trans. Ind. Electron., vol. 48, no. 6, pp. 1118-1127, Dec. 2001.

[23] M. Lamich, J. Balcells, J. Garcia, D. Gonzalez, and J. Gago, "New structure for three phase four wires hybrid active filters," in Proc. IEEE Ind. Electron. Conf. (IECON 2006), pp. 1603-1608.

[24] P. Rodriguez, J. Pou, J. Bergas, J. I. Candela, R. P. Burgos, and D. Boroyevich, "Decoupled double synchronous reference frame PLL for power converters control," IEEE Trans. Power Electron., vol. 22, no. 2, pp. 584-592, Mar. 2007.

[25] "Power filter with four-branch star topology for simultaneous cancellation of positive-, negative-, and zero-sequence," (in Spanish), Spanish patent applications P200700209, Jan. 22, 2007.

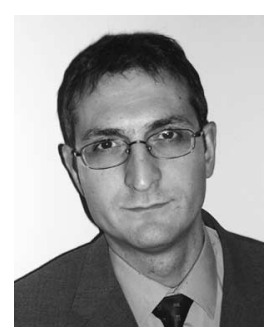

Pedro Rodríguez (S'99-M'04) received the B.S. degree from the University of Granada, Granada, Spain in 1989, and the M.S. and Ph.D. degrees from the Technical University of Catalonia (UPC), Barcelona, Spain, in 1994 and 2004, respectively, all in electrical engineering.

During 1990, he was an Assistant Professor at UPC, where he became an Associate Professor in 1993 and is currently the Head of the Research Group on Renewable Electrical Energy Systems, Department of Electrical Engineering. During 2005, he was a Researcher in the Center for Power Electronics Systems, Virginia Polytechnic Institute and State University, Blacksburg. During 2006, he was a Researcher in the Institute of Energy Technology, Aalborg University, Aalborg, Denmark. He has authored or coauthored more than 100 papers in technical journals and conferences, and holds two patents. His current research interests include power conditioning, integration of distributed energy systems, and control of power converters.

Dr. Rodriguez is a member of the IEEE Power Electronics Society, the IEEE Industrial Electronics Society, and the IEEE Industry Application Society.

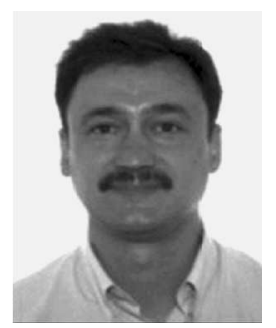

J. Ignacio Candela (S'99-M'04) received the B.S. and M.S. degrees in industrial engineering in 1987 and 2000, respectively, from the Technical University of Catalonia (UPC), Barcelona, Spain, where he is currently working toward the Ph.D. degree in electrical engineering.

During 1991, he was an Assistant Professor at UPC, where he became an Associate Professor in 1993. He has authored or coauthored more than 30 published technical papers, and has been involved in several industrial projects and educational programs in the fields of power quality conditioning and motor drives. His current research interests include power conditioning, integration of distributed energy systems, and control of power converters and motor drives.

Dr. Candela is a member of the IEEE Power Electronics Society, the IEEE Industrial Electronics Society, and the IEEE Industry Application Society.

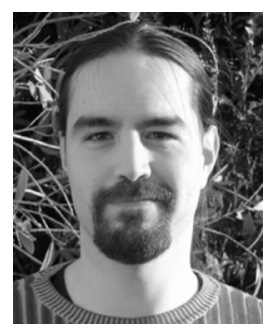

Alvaro Luna (S'07) received the B.Sc. and M.Sc. degrees in electrical engineering in 2001 and 2005, respectively, from the Universitat Politecnica de Catalunya (UPC), Barcelona, Spain, where he is currently working toward the Ph.D. degree.

He joined the faculty of UPC in 2005, where he is currently an Assistant Professor. His research interests include wind turbines control, integration of distributed generation, and power conditioning.

Mr. Luna is a Student Member of the IEEE Power Electronics Society, the IEEE Industrial Electronics Society, and the IEEE Industrial Applications Society.



Lucian Asiminoaei (S'03-M'06) received the M.Sc. degree in electrical engineering from the Faculty of Shipbuilding and Electrical Engineering, Section of Power Electronics and Advanced Control Systems, "Dunarea de Jos" University of Galati, Galati, Romania, in 1997, and the Ph.D. degree from Aalborg University, Aalborg, Denmark, in 2006.

From 1996 to 1999, he was a Maintenance Engineer at the Iron and Steel Works Sidex S.A., Galati. During 1999, he was a Hardware Engineer in the Information Technology (IT) Department, IspatSidex LNM Group, Galati. During 2003, he joined the Institute of Energy Technology, Department of Power Electronics and Drives, Aalborg University, where he was involved in projects sponsored by Danfoss Drives A/S, Graasten, Denmark and Power Lynx A/S, Denmark. He was a Visiting Scholar at Texas A\&M University, College Station. He is currently with Danfoss Drives A/S. His current research interests include harmonic mitigation, harmonic measurement, and design of active and hybrid filters. 


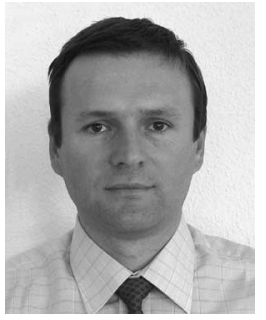

Remus Teodorescu (S'94-A'97-M'99-SM'02) received the Dipl.Ing. in electrical engineering from the Polytechnical University of Bucharest, Bucharest, Romania, in 1989, and the Ph.D. degree in power electronics from the University of Galati, Galati, Romania, in 1994.

From 1989 to 1990 , he was with the Iron and Steel Plant, Galati. He was an Assistant Professor in the Department of Electrical Engineering, University of Galati, where he has been an Assistant Professor since 1994 and was appointed as the Head of the Power Electronics Research Group in 1996. In 1998, he joined the Department of Power Electronics and Drives, Institute of Energy Technology, Aalborg University, Aalborg, Denmark, where he is currently a Full Professor. He has authored or coauthored more than 60 papers and one book. He holds two patents. His current research interests include power converters for renewable energy systems, solar cells, multilevel inverters, digital control, and computer simulations of advanced electrical drives.

Dr. Teodorescu is a corecipient of the Technical Committee Prize Pape Awards at the IEEE Industry Applications Society (IAS) 1998 and the Optimization of Electrical and Electronic Equipment (OPTIM) Asea Brown Boveri (ABB) Prize Paper Award at OPTIM 2002.

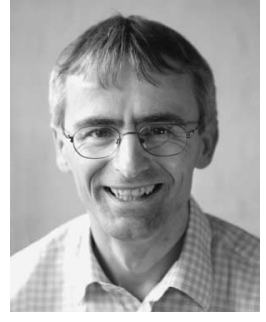

Frede Blaabjerg (S'86-M'88-SM'97-F'03) was born in Erslev, Denmark, on May 6, 1963. He received the M.Sc.E.E. and Ph.D. degrees from Aalborg University, Aalborg, Denmark, in 1987 and 1995, respectively.

From 1987 to 1988 , he was with ABB-Scandia, Randers, Denmark. During 2000, he was a Visiting Professor in the University of Padova, Padova, Italy, as well as a Part-Time Program Research Leader in wind turbines at the Research Center Risoe, Risoe, Italy. During 2002, he was a Visiting Professor in the Curtin University of Technology, Perth, Australia. He is currently a Full Professor in power electronics and drives and the Dean of the Faculty of Engineering and Science, Aalborg University. He is involved in more than 15 research projects within the industry including the Danfoss Professor Programme in Power Electronics and Drives. He has authored or coauthored more than 350 publications in his research fields including the book Control in Power Electronics (New York: Academic, 2002). He is an Associate Editor for the Journal of Power Electronics and Elteknik. His current research interests include power electronics, static power converters, ac drives, switched reluctance drives, modeling, characterization of power semiconductor devices and simulation, power quality, wind turbines, and green power inverters.

Prof. Blaabjerg was an Associate Editor of the IEEE TRANSACTIONS ON INDUSTRY APPLICATIONS, and is currently the Editor-in-Chief of the IEEE TRANSACTIONS ON POWER EleCtronics. He is a member of the European Power Electronics and Drives Association, the IEEE Industry Applications Society Industrial Drives Committee, the Industry Power Converter Committee, the Power Electronics Devices and Components Committee, and the IEEE Industry Application Society. From 1997 to 2003, he was a member of the Danish Technical Research Council in Denmark, where he was the Chairman from 2001 to 2003. He has also been the Chairman of the Danish Small Satellite Programme and the Center Contract Committee. During 2001, he became a member of the Danish Academy of Technical Science. During 2003, he became a member of the Academic Council. From 2002 to 2003, he was a member of the Board of the Danish Research Councils. In 2004, he became the Chairman of the Programme Committee on Energy and Environment. He received the 1995 Angelos Award for his contribution in modulation technique and control of electric drives, the Annual Teacher Prize from Aalborg University in 1995, the Outstanding Young Power Electronics Engineer Award from the IEEE Power Electronics Society in 1998, five IEEE Prize Paper Awards during the last six years, the C. Y. O'Connor Fellowship from Perth, Australia in 2002, the Statoil Prize for his contributions in Power Electronics in 2003, and the Grundfos Prize in acknowledgment of his international scientific research in power electronics in 2004. 